\title{
A Role and Potential of E-Krishimitra Tool in Usability Improvement of Agricultural Domain
}

\author{
Sushopti Gawade \\ Pillai Collage of Engineering, New Panvel \\ Research Scholar, PAHER Udaipur, and Faculty, \\ PCE
}

\author{
Varsha Turkar, PhD \\ Don Bosco Collage of Engineering, Fatorda, Goa \\ IEEE Senior Member, Professor DBCOE
}

\begin{abstract}
The agricultural sector in India has challenges, such as requirement for increase of food production and produce. In addition, the agricultural sector has important effects due to global factors and rapid changes. These truths show that there is great necessity for information technologies (IT), which can be used to handle the challenges and changes and to progress agricultural production and marketing. Though, in India, the power of IT is not fully exploited in agriculture. Execution of IT in agricultural segment and rural parts is slow in comparison to the other sectors of the economy where IT has been implemented at rapid speed. The e-Krishimitra tool has been developed using

information and communication technology to make the life of Indian famers easy. The tool provides various services like location-based service, Best crop suggestion, Crop disease diagnosis, guidance for government scheme and regional language support. Only the tool development is not sufficient, but the effectiveness of the tool should be evaluated to know whether it is used by maximum population or not. This paper presents detailed results of usability evaluation of e-Krishimitra tool.
\end{abstract}

\section{Keywords}

Digital Media, Agriculture, Usability, Agricultural Services, Usability Evaluation.

\section{INTRODUCTION}

Digital information available online is required to be organized in some form to derive relevant information. Sharing of such information to farmers is possible using Information and Communication Technologies (ICT). A simple and usable interface provides information to the farmers to make a certain decision in time to improve the agriculture produce like crop yield. Farming community strongly believes in traditional methods. In this digital era all the farming activities are available in digital form. Websites as a digital platform plays role like content management system or learning management system. Many farmers are not using these available services. There are some problems like awareness about these tools, lethargic attitude towards automated systems, complexity to use digital media, and digital illiteracy to handle all these tools. Lack of simplicity and learnability to the sources of information is one of the major issues. This is where usability in agriculture comes into existence. These issues lead to think about usability of digital media in agriculture domain. Ease of use of websites is very much needed in agricultural fields to remove the digital gap. So as a solution to various issues there is need to develop highly usable digital media.

An e-Krishimitra tool is designed and developed with ICT by incorporating different services to provide solutions to farmers. It aims to develop the rural farming communities in India by providing seamless access to vital agricultural information and services. It is a user-centered information system with an ease of use, simple and learnable, community-oriented design that aims to promote professional growth of the rural farmers [1]. The eKrishimitra online service provider tool is available in the form of mobile app and website as content management system. It also provides different videos to the farmers about agriculture schemes, which helps them to learn easily and quickly about the schemes like Fasal Bima Yojana initiated by Government of India for them.

The "www.ekrishimitra.org" is an online service provider tool which has an agricultural service to help farmers for their day to day farming activities.

This tool is available in three languages Marathi, Hindi and English. The information of all services is accessible in the form of text, audio and some guidelines about schemes in video [2]

\section{USABILITY}

Usability is the overall measurement of the satisfaction of interactions a user has with a product or system such as a web site, software application, mobile technology, or user-operated device. A high level of satisfaction occurs when users find a web site that is useful and more usable, this s termed as an "engaging user experience". The ISO 9241-11 standard [23] defines usability as "the extent to which a product can be used by specified users to achieve specified goals with effectiveness, efficiency, and satisfaction in a specified context of use". The various evaluation parameters are as follows:

- Usefulness: The users should feel comfortable to use.

- Efficiency [23]: The resources expended concerning the accuracy and completeness with which users achieve goals.

- Satisfaction: The comfort and acceptability of use.

- Memorability: Easy to move from one to another.

- Universality: Close to local language. 


\section{THE INTERFACE DESIGN OF E- KRISHI MITRA}

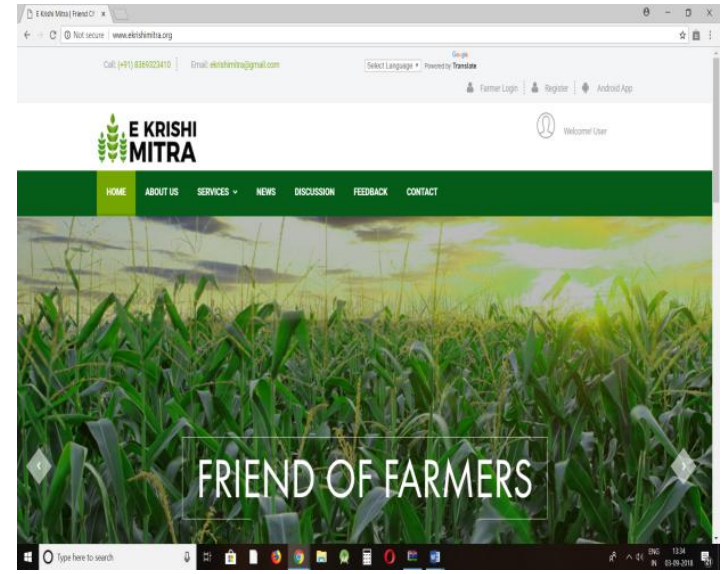

Fig. 1: Interface of e-Krishimitra

The online service provider tool e-Krishimitra[22] (as shown in Fig. 1) has the following functions for users: 1) Government Scheme Information - E-Learning (Providing information of funding schemes, insurance claim form and instructions of PMFBY in the form of multimedia, i.e., text, audio, and video.) 2) Best crop suggestion 3) Crop yield estimation 4) Crop Disease Diagnosis 5) Multilingual support (English, Marathi and Hindi) [1].

\section{USABILITY EVALUATION OF E- KRISHIMITRA}

The four primary methods [5], [19] of evaluating user interfaces are as follows:

1. Automatically: In this approach usability measures computed by running a user interface specification through some program like SEOptimer, Qualidator, etc.

2. Empirically: In this case usability assessed by testing the interface with real users

3. Formally: In this method, exact models and formulas are used to calculate usability measures like SUS Scale [23].

4. Informally: It is based on rules of thumb and the general skill and experience of the evaluators.

Usability evaluation of the services of the e-Krishimitra tool by first and third method respectively is discussed in this paper. The first method uses automated tools like SEOptimer, Qualidator, etc. The third method is called a formal process. The empirical method uses interface testing by actual users. This method has three usability metrics effectiveness, efficiency, and satisfaction to evaluate the performance of the product

\subsection{Effectiveness Performance Metric}

They are three performance metrics. First metric effectiveness [23] calculated by measuring the completion rate. Referred the fundamental usability metric, the completion estimated by assigning a binary value of ' 1 ' if the test participant manages to complete a task and ' 0 ' if he/she does not [23], [1]. It is computed using following expression.

Effectiveness $=\frac{\text { No of tasks completed successfully }}{\text { Total number of tasks undertaken }} \times 100$

\subsection{Efficiency Performance Metric}

Second performance metric is about efficiency [23] which is related to the time (which is measured in seconds or minutes) taken by the users to complete any task. The time is taken to finish any work can directly calculate by subtracting the start time from the end time. The formula to calculate efficiency is: Task Time $=$ End Time - Start Time [23] [24].

Efficiency can be calculated using either of the two ways:

Time-Based Efficiency [23]:

$$
\text { Time based Efficiency }=\frac{\sum_{j=1}^{R} \Sigma_{i=1}^{N} \frac{n i j}{t i j}}{N R}
$$

Where $\mathrm{N}=$ Total number of tasks undertaken $\mathrm{R}=$ The total number of consumers/users $\mathrm{N}$ ij The result of task i undertaken by user $\mathrm{j}$.

$\mathrm{N}_{\mathrm{J}}=1$; if the consumer completes the task otherwise $\mathrm{N}_{\mathrm{J}}=0$; if the consumer does not complete the work successfully. $t_{i j}=$ The time spent by consumer $j$ to complete the task $i$. If the job is not complete, then time is measured until the moment the user quits the work [23] [24]

Overall Relative Efficiency: The Overall Relative Efficiency [23] utilizes the ratio of the time taken by the consumers/users who accomplished the task about the total time taken by all consumers/users. The equation represented as shown below

$$
\text { Overall Relative Efficiency }=\frac{\sum_{j=1}^{R} \sum_{i=1}^{N} n i j t i j}{\sum_{j=1}^{R} \sum_{i=1}^{N} t i j} \times 100 \%
$$

\subsection{Satisfaction Performance Metric}

Satisfaction performance metric has evaluated by conducting an online survey with identified users. Simple questionnaire method has been used to get opinions of the users to fulfill this parameter.

\section{EVALUATION BY AUTOMATED TOOLS}

Usability evaluation method defines the accuracy of the assessment. The different estimation methods may give different results for the same system. There are different ways to assess the quality of the website [3]. Following are some identified website evaluation automated tools.

Website Grader: It is a free online tool which tells about page load time, how well the site adjusts to mobile devices, security, performance and core elements of SEO [14]. Evaluation of eKrishimitra tool is done by website grader on $14^{\text {th }}$ Nov 2018. Results are shown in Table 1.

Qualidator: The Qualidator website Analyzer is an online tool. It is also available for Windows. It performs automated validation of an entire website by referring pages, i.e., page by page. Qualidator tool (Quality Validator) performs 60-70 computerized tests on the sites to find out the Usability, SEO, Accessibility, and Quality of websites. Qualidator gives the Usability in percentage Value. This tool benefits website designers, developers, and owners of the site to improve their websites [13]. Results for e-Krishimitra by this automated tool shown in Table 1. 
Table 1: e-Krishimitra evaluation by tools

\begin{tabular}{|c|c|c|c|}
\hline $\begin{array}{c}\text { CRITERIA/ } \\
\text { TOOLS }\end{array}$ & $\begin{array}{c}\text { WEBSITE } \\
\text { GRADER }\end{array}$ & $\begin{array}{c}\text { QUALIDA } \\
\text { TOR }\end{array}$ & BY BOTH \\
\hline Performance & 48 & NA & 48 \\
\hline Accessibility & NA & 76.5 & 76.5 \\
\hline Mobile & 100 & NA & 100 \\
\hline SEO & 50 & 65.2 & 59 \\
\hline Security & 100 & NA & 100 \\
\hline Usability & NA & 75.9 & 75.9 \\
\hline Overall & $\mathbf{7 0}$ & $\mathbf{7 2 . 9}$ & $\mathbf{7 2}$ \\
\hline
\end{tabular}

Table 1 shows that the overall usability of e-Krishimitra tool by an automated program. It is $72 \%$.

\section{EVALUATION OF USER INTERFACE OF E-KRISHIMITRA BY FORMULA (SUS) METHOD}

System Usability Scale (SUS): The System Usability Scale (SUS) [21] [23] [24] provides a

"quick and dirty," reliable tool for measuring usability. It consists of a 10-item questionnaire with five response options for respondents; from strongly agree to disagree.

SUS is created by John Brooke in 1986. It allows you to evaluate a wide variety of products and services, including hardware, software, mobile devices, websites, and applications. The System Usability Scale is a Likert scale which includes ten questions which users of website will answer. Participants will rank each item from 1 to 5 based on how much they agree with the statement they are reading [23]. Rating 5 means they agree and one means they disagree entirely.

SUS has become an industry standard, with references in over 1300 articles and publications. The noted benefits of using SUS include that it is a natural scale to administer to participants and can be used on small sample sizes with reliable results.

\section{Procedure to calculate the SUS score:}

- For odd items: subtract one from the user response

- For even-numbered items: subtract the user responses from 5

- Scales all values from 0 to 4 (with four being the most positive response)

- Add up the converted responses for each user and multiply that total by 1.25 . Here translates the range of possible values from 0 to 100 instead of from 0 to 80 .

Test conduction for identified users: With the help of questions given in Table 2, the test has been conducted for 20 users. Responses are stored in an excel sheet for the same. Finally, the SUS score is computed for the e-Krishimitra tool as shown in Fig. 2.
Table 2: Questions for SUS usability test

\begin{tabular}{|c|c|}
\hline Parameter & Questions \\
\hline \multirow{4}{*}{ Efficiency } & $\begin{array}{l}\text { The information and contents are useful } \\
\text { and well organized }\end{array}$ \\
\hline & The website is unnecessarily complicated. \\
\hline & $\begin{array}{l}\text { It helps to perform the task quickly, and } \\
\text { web pages navigate efficiently. }\end{array}$ \\
\hline & The website has too much inconsistency. \\
\hline \multirow{4}{*}{ Learnability } & It is easy to learn to use it. \\
\hline & It is difficult to use it quickly. \\
\hline & $\begin{array}{c}\text { It provides flexible user options (i.e., } \\
\text { information is available in audio/video } \\
\text { format) }\end{array}$ \\
\hline & $\begin{array}{l}\text { The information provided by a system is } \\
\text { difficult to understand and interpret. }\end{array}$ \\
\hline \multirow{4}{*}{$\begin{array}{l}\text { User's } \\
\text { satisfaction }\end{array}$} & $\begin{array}{l}\text { I would recommend it to family and } \\
\text { friends. }\end{array}$ \\
\hline & It is unpleasant to use. \\
\hline & I am satisfied with the website. \\
\hline & I found it uninteresting and dull. \\
\hline \multirow{4}{*}{ Ease of use } & $\begin{array}{l}\text { An interface is smooth, user-friendly and } \\
\text { straightforward. }\end{array}$ \\
\hline & $\begin{array}{c}\text { An interface has no images and is not that } \\
\text { effective. }\end{array}$ \\
\hline & $\begin{array}{c}\text { The website saves me time and meets my } \\
\text { needs. }\end{array}$ \\
\hline & It is not flexible. \\
\hline \multirow{2}{*}{ Memorability } & $\begin{array}{l}\text { The tool is easy to remember, and I can } \\
\text { confidently use it every time. }\end{array}$ \\
\hline & $\begin{array}{l}\text { The tool is confusing to use after a long } \\
\text { time. }\end{array}$ \\
\hline \multirow{2}{*}{ Universality } & $\begin{array}{l}\text { Website content is available in local } \\
\text { languages (other than English) }\end{array}$ \\
\hline & $\begin{array}{c}\text { It is not easy to understand information } \\
\text { about the website of other languages (i.e., } \\
\text { Hindi, Marathi) }\end{array}$ \\
\hline
\end{tabular}

\section{Interpretation of Scores:}

Based on research [21] ,[22], [23] a SUS score above a 68 would be considered above average and anything below 68 is below average; however, the best way to interpret the results involves "normalizing" the scores to produce a percentile ranking. A SUS score of 68 is in the $50^{\text {th }}$ percentile, which means the score is higher than 50 percent of all tested systems and applications. SUS scores also translated into letter grades, which may be helpful for communication. The score 91.3 for e-Krishimitra is above average. SUS scores are given below in Table 3 . The average SUS score for e-Krishimitra usability is 91.38. 
Table 3: SUS scores for e-Krishimitra tool

\begin{tabular}{|c|c|}
\hline USERS & MODIFIED SUS SCORE \\
\hline U1 & 96.25 \\
\hline $\mathrm{U} 2$ & 95 \\
\hline $\mathrm{U} 3$ & 86.25 \\
\hline $\mathrm{U} 4$ & 96.25 \\
\hline U5 & 100 \\
\hline U6 & 92.5 \\
\hline U7 & 82.5 \\
\hline U8 & 72.5 \\
\hline U9 & 87.5 \\
\hline U10 & 96.25 \\
\hline U11 & 82.5 \\
\hline U12 & 87.5 \\
\hline U13 & 92.5 \\
\hline U14 & 90 \\
\hline U15 & 88.75 \\
\hline U16 & 95 \\
\hline U17 & 96.25 \\
\hline U18 & 95 \\
\hline U19 & 98.75 \\
\hline $\mathrm{U} 20$ & 96.25 \\
\hline
\end{tabular}

\section{USABILITY EVALUATION OF E-KRISHIMITRA BY PERFORMANCE METRICS}

A. Effectiveness evaluation of e-Krishimitra

There are three necessary steps to calculate the effectiveness [23] of any product.

Step1: Selection of the best task list.

Step2: Calculate task completion rate of some sample users.

Step3: Do calculations by using a formula given in equation (1).

For this service of e-Krishimitra, 10 tasks are selected, and observations have noted for ten random users. Fig. 2 Shows the details of jobs and task completion rate for this service.

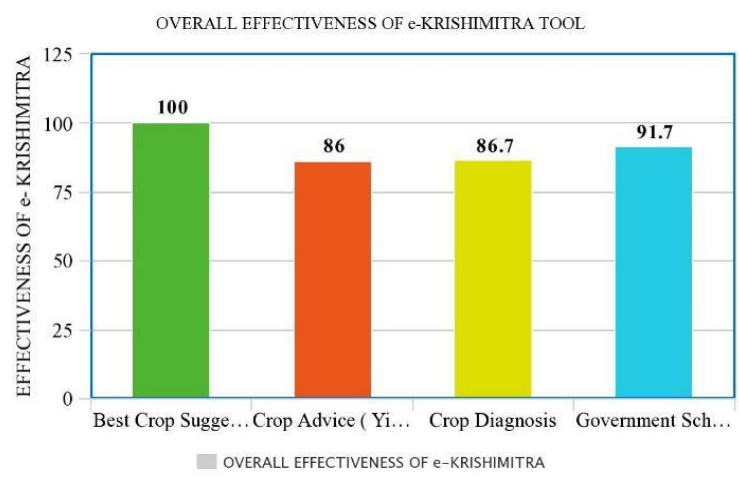

Fig. 2: Task completion table for e-Krishimitra

Overall Effectiveness of e-Krishimitra tool

$=$ Average (effectiveness of all services)

$=(100+86+86.7+91.7) / 4$

$=\mathbf{9 1 . 1 \%}$

\section{B. Efficiency evaluation of e-Krishimitra}

Efficiency [23] calculation for this service has three steps.

Step1: To select tasks and users.

In this step, ten tasks selected for 20 sample users.

Step2: To calculate time-based efficiency. The formula provided by Equation (2) is used to calculate time-based efficiency.

Step 3: To calculate the relative and overall efficiency of this which? service of e-Krishimitra tool.

$\mathrm{N}=$ The total number of per task per user $=1$

$\mathrm{R}=$ The number of users $=20$. Detail shown in Fig. $3 \mathrm{a}$ and Fig. $3 b$. 
$N i j=$ result of task if successfully completed then 1 if not then 0 Tij= time spent by user in minutes

\begin{tabular}{|c|c|c|c|}
\hline \multirow[b]{2}{*}{ Users } & \multicolumn{3}{|c|}{ T1 } \\
\hline & Nij & Tij & $\begin{array}{c}\mathrm{Nij} / \\
\mathbf{T i j}\end{array}$ \\
\hline U1 1 & 1 & 1 & 1 \\
\hline $\mathbf{U} 2$ & $\overline{1}$ & 2 & 0.5 \\
\hline U3 & 1 & 3 & 0.33 \\
\hline U/4 & 1 & 1 & 1 \\
\hline U5 & 1 & 2 & 0.5 \\
\hline U6 6 & 1 & 1 & 1 \\
\hline U7 & 1 & 3 & 0.33 \\
\hline I8 8 & 1 & 2 & 0.5 \\
\hline U9 & 1 & 1 & 1 \\
\hline U10 & 1 & 2 & 0.5 \\
\hline U11 & 1 & 1 & 1 \\
\hline U 12 & 1 & 1 & 1 \\
\hline U13 & 1 & 1 & 1 \\
\hline U 14 & 1 & 2 & 0.5 \\
\hline U15 & 1 & 3 & 0.33 \\
\hline U 16 & 1 & 1 & 1 \\
\hline U17 17 & 1 & 1 & 1 \\
\hline U 18 & 1 & 2 & 0.5 \\
\hline บ19 & 1 & 2 & 0.5 \\
\hline \multirow[t]{3}{*}{ U 20} & 1 & 1 & 1 \\
\hline & & sum & 14.5 \\
\hline & \multicolumn{3}{|c|}{$\begin{array}{c}\mathrm{E}-14.5 /(1 * 20)-14.5 \\
/ 20-0.725 \\
\text { goals/minutes }\end{array}$} \\
\hline
\end{tabular}
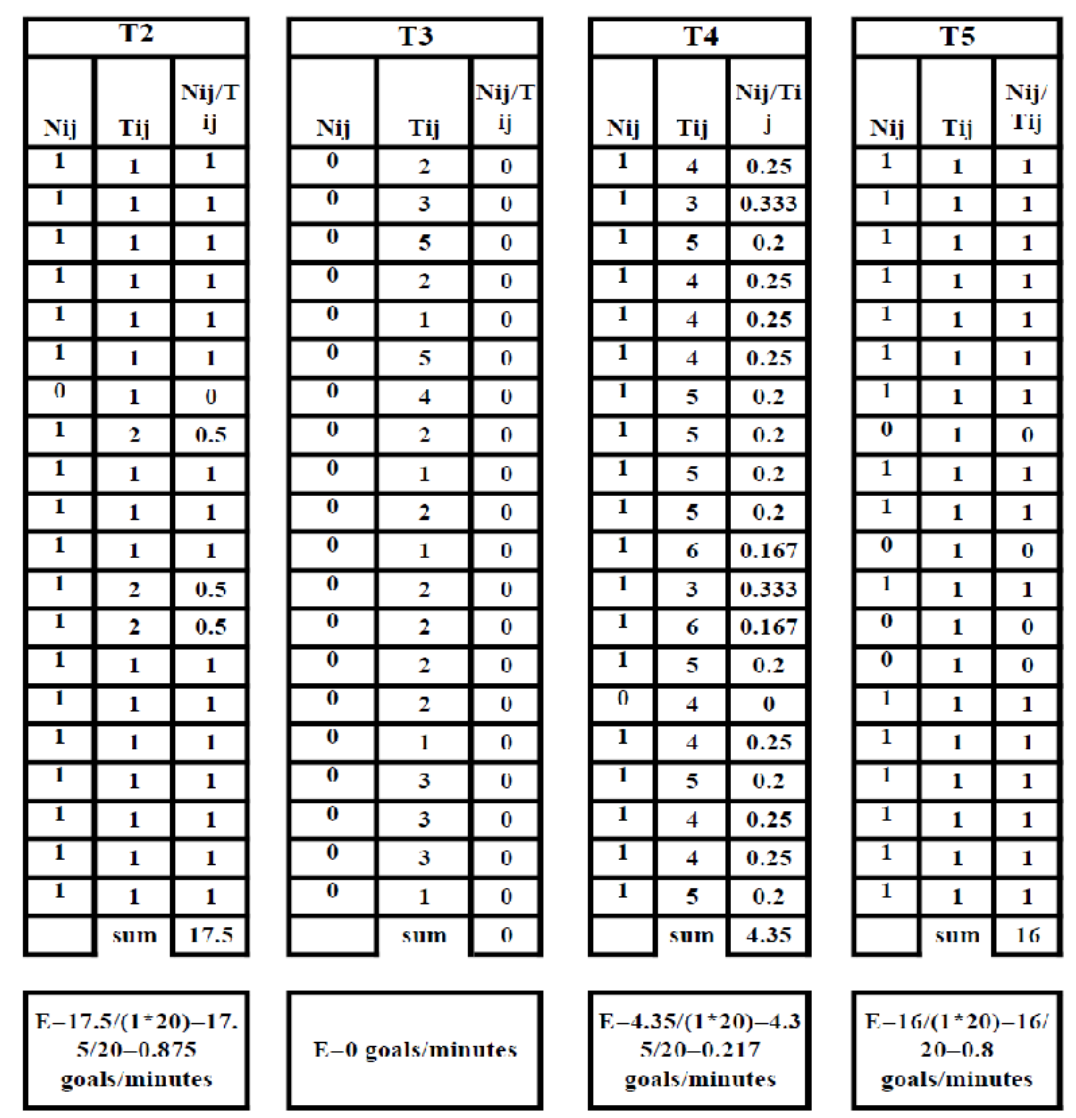

Fig. 3a: Efficiency rate for e-Krishimitra by users
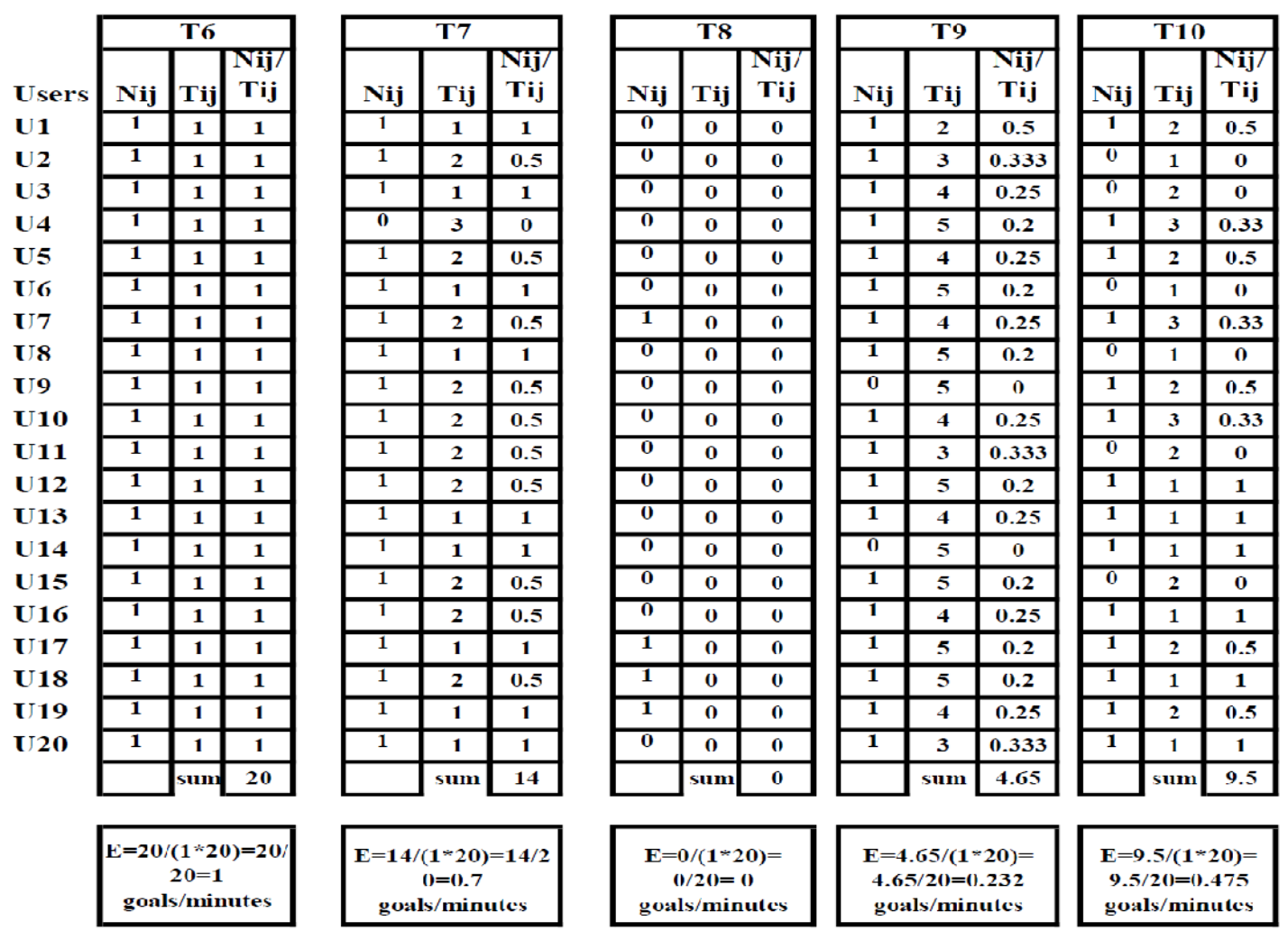

Fig. 3b: Efficiency rate for e-Krishimitra by users 


\author{
Average Task Efficiency \\ $=(0.725+0.875+0+0.217+0.8+1+0.7+0+0.232+$ \\ $0.475) / 10$ \\ $=5.02$ goals $/$ minutes \\ Overall task efficiency \\ = Average task efficiency)/ 10] $* 100$ \\ $=[5.024 / 10] * 100$ \\ $=50.24 \%$
}

A. Satisfaction evaluation of e-Krishimitra

An online questionnaire survey method used to measure satisfaction usability parameter. A simple questionnaire with satisfaction-related questions [20] is designed. There are four questions to measure the satisfaction level of users for this tool. Each question has been given a scale of 1 to 5(Minimum to Maximum).

Questions are shown in Fig. 4. All the responses by identified users stored in an excel sheet. With the help of data collected, results in the percentage shown in Table 4 and Fig. 4.

Table 4: Survey Details for Satisfaction

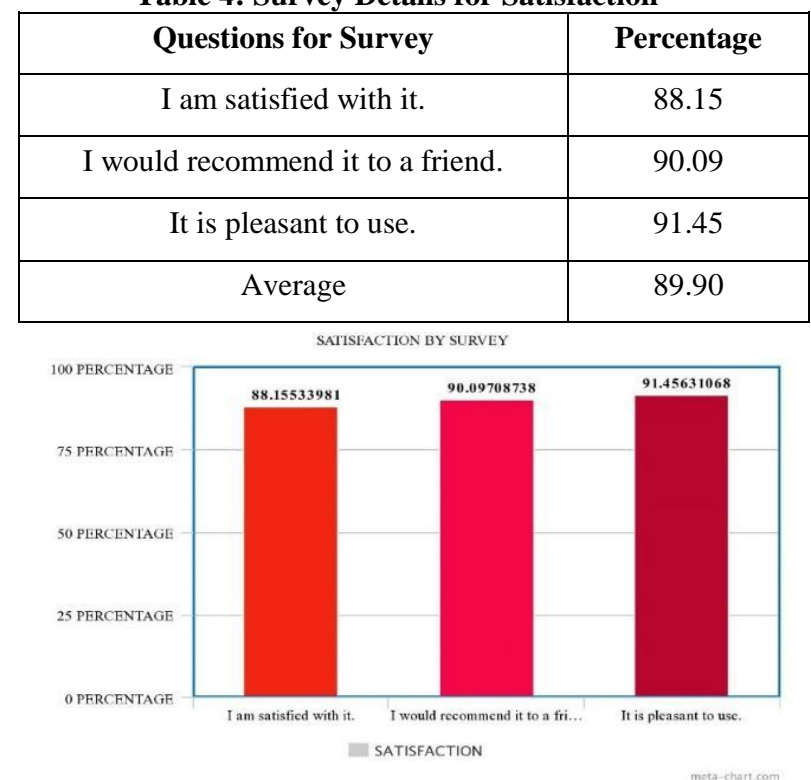

Fig. 4: Satisfaction performance metric.

Usability performance with effectiveness, efficiency, and satisfaction for this tool is $91.1 \%, 50.24 \%$ and $89.9 \%$ respectively.

\section{Usability performance}

$=($ Effectiveness + Efficiency + Satisfaction $) / 3$

$=(91.3+50.24+89.9) / 3$

$=\mathbf{7 7 . 1 4 \%}$

\section{CONCLUSION}

From the above study it is observed that the existing information in the area of agriculture is made available easily with an eKrishimitra tool. It has a straightforward and pleasant interface. This tool has six different services for the farmer community. It provides Government scheme management for farmers, crop yield estimation for the selected district, Best crop suggestion for the selected region, crop diagnosis for three crops cucumber, tomato and wheat. This tool provides all information in three languages Hindi, English, Marathi as it tries to minimize the language barrier for farmers.

It can be easily extendable to other regional languages. It also provides guidelines and information in text audio and video for all services. The detailed result for usability evaluation is presented with usability metrics. Usability evaluation results of e-Krishimitra online service provider tool by considering its effectiveness, efficiency and satisfaction are $91.7 \%, 50.24 \%$ and $89.9 \%$ respectively.

\section{REFERENCES}

[1] Samruddhi Khandare, Sushopti Gawade, Dr. Varsha Turkar, "Design and Development of E-Farm with S.C.H.E.M.E," 2017 International Conference on Recent Innovations in Signal Processing and Embedded Systems (RISE), 2017.

[2] Komal Raikar, Sushopti Gawade, Varsha Turkar. "Usability improvement with crop disease management as a service," 2017 International Conference on Recent Innovations in Signal Processing and Embedded Systems (RISE), 2017

[3] Peishan Tsai," A survey of empirical usability evaluation methods," "Digital India: Unleashing Prosperity"- Indian Journal of Applied Research, April-2016.

[4] Jinal Jani, Girish Tere, "Digital India: A Need of Hours"International Journal of Advanced Research in Computer Science and Software Engineering, August-2015.

[5] Prof. Kumbharde M. V., Ghodke Tushar D., Devde Nitin N., Agwan Sagar C., Kudal Yogesh N, "E- Farming: An Innovative Approach for an Indian Farmer"- International Journal on Recent and Innovation Trends in Computing and Communication, September-2015.

[6] Sukhpuneet Kaur, Kulwant Kaur, Parminder Kaur, "Analysis of Website Usability Evaluation Methods"International Conference on Computing for Sustainable Global Development, 2016.

[7] S. Gopinath, V. Senthooran, N. Lojenaa, T. Kartheeswaran, "Usability and Accessibility Analysis of Selected Government Websites in Sri Lanka," 2016.

[8] S. A. Adepoju, I. S. Shehu, "Usability Evaluation of Academic Websites Using Automated Tools"- International Conference on User Science and Engineering, 2014.

[9] Ahmad A. Al-Ananbeh, "Website Usability Evaluation and Search Engine Optimization for Eight Arab University Websites," 2012.

[10] Fang Liu, "Usability Evaluation of websites.", 2008.

[11] Ben Shneiderman and Catherine Plaisant., "Designing the User Interface," 2015.

[12] Savita Pundalik Teli and Santoshkumar Biradar, "Effective Email Classification for Spam and Non-Spam" International Journal of Advanced Research in Computer Science and Software Engineering, June 2015.

[13] Haiyi Zhang and Di Li, "Naïve Bayes Text Classifier" IEEE International Conference on Granular Computing, 2007.

[14] Rishin Haldar and Debajyoti Mukhopadhyay, "Levenshtein Distance Technique in Dictionary Lookup Methods: An Improved Approach," 2013. 
[15] Tian Xia, "An Edit Distance Algorithm with Block Swap."The 9th International Conference for Young Computer Scientists, 2008.

[16] Hitarthi Bhatt, Shraddha Mehta, and Lynette R. D'Mello, "Use of ID3 Decision Tree Algorithm for Placement Prediction", Hitarthi Bhatt et al., / (IJCSIT) International Journal of Computer Science and Information Technologies, Vol. 6 (5), 2015, 4785-4789, 2015

[17] Rupali Bharadwaj and Sonia Vatta, "Implementation of ID3 Algorithm", International Journal of Advanced Research in Computer Science and Software Engineering Volume 3 - Issue 6, June 2013.

[18] S. Veenadhari, Dr. Bharat Mishra and Dr. C. D. Singh, Soybean "Productivity Modelling using Decision Tree Algorithms, International Journal of Computer Applications (0975 - 8887) Volume 27- No.7, August 2011.
[19] Levenshtein Distance, in Three Flavors, by Michael Gilleland, Merriam Park Software https://people.cs.pitt.edu/ kirk/cs1501/Pruhs/Spring2006/as signments/editdistance/Levenshtein\%20Distance.htm.

[20] Comparison of usability evaluation methods, Genise, Pauline. "Usability Evaluation: Methods and Techniques: Version 2.0" August 28, 2002. University of Texas https://en.wikipedia.org/wiki/Comparison_of_usability_eva luation_methods.

[21] www.usability.gov.in accessed on Jan 2018

[22] Sushopti Gawade, Dr. Varsha Turkar, "Design and Development of 'e-krishimitra' service provider tool " ICCUBEA 2017 "under press.

[23] www.usabilitygeek.com accessed on Jan 2018

[24] www.usability.gov accessed on Dec 2017

[25] https://measuringu.com/sus/ accessed on Jan 2018 